\title{
28 Research Square \\ Use of bacterial cellulose in the textile industry and the wettability challenge - a review
}

Ana Paula Provin ( $\square$ ana_provin@yahoo.com.br)

Universidade do Sul de Santa Catarina https://orcid.org/0000-0003-4441-5657

Victória Oliva dos Reis

Universidade do Sul de Santa Catarina

Stefany Espindola Hilesheim

Universidade do Sul de Santa Catarina

Ritanara Tayane Bianchet

Universidade do Sul de Santa Catarina

Ana Regina de Aguiar Dutra

Universidade do Sul de Santa Catarina

Anelise Leal Vieira Cubas

Universidade do Sul de Santa Catarina

\section{Research Article}

Keywords: Bacterial cellulose, Wettability, Biotextile, Sustainability

Posted Date: March 10th, 2021

DOI: https://doi.org/10.21203/rs.3.rs-246462/v1

License: (c) (i) This work is licensed under a Creative Commons Attribution 4.0 International License. Read Full License

Version of Record: A version of this preprint was published at Cellulose on July 10th, 2021. See the published version at https://doi.org/10.1007/s10570-021-04059-3. 


\section{Abstract}

Bacterial cellulose (BC) has been studied as an alternative material in several segments of the food, pharmaceutical, materials and textile industries. The importance of $B C$ is linked to sustainability goals, since it is an easily degradable biomaterial of low toxicity to the environment and is a renewable raw material. For use in the textile area, bacterial cellulose has attracted great interest from researchers, but it presents some challenges, notably hydrophilicity due to its porous structure. This bibliometric review article gathers studies and methods related to minimizing the hydrophilicity of bacterial cellulose in order to expand its applicability in the textile industry. The databases consulted were ScienceDirect, ProQuest and Web of Science, the documents investigated were scientific articles and the time period investigated was between 2015 and 2021. The discussion is focused on the applicability of BC in the textile industry, highlighting the research needs, especially with regard to reducing wettability.

\section{Introduction}

The textile industry is associated with numerous environmental problems. Large amounts of harmful waste are generated at all stages of clothing manufacturing, with negative environmental and social impacts, such as landfill consumption, low resource efficiency and air/soil pollution (Chan et al. 2018; Correia and Silva 2019; Sandvik and Stubbs 2017). Although the garments are used for a relatively long period, even by several consecutive users, studies have demonstrated that the manufacture of cotton garments, for example, is extremely polluting.

To obtain $1 \mathrm{~kg}$ of cotton fiber, 29 tons of water are consumed. In total, $25 \%$ of all insecticides and more than $11 \%$ of pesticides used globally in agriculture are applied to cotton crops. The amount of material that requires disposal presents a real challenge for the fashion industry. This quantity has increased notably in the past 50 years, with around 15 million tons of used textile waste currently being generated each year in the USA (Domskiene et al. 2019).

The quest to make the fashion industry more sustainable has increasingly directed designers and scientists to focus on biomaterials, such as bacterial cellulose (BC), and their biocompatible properties. $\mathrm{BC}$ is environmentally friendly, safe for the human body and considered a renewable raw material, and one way to obtain it is through the kombucha fermentation process (Domskiene et al. 2019). It is a natural, non-woven material, firmly structured, with an appearance that resembles leather (Chan et al. 2018; Domskiene et al. 2019; Sederavičiūtè et al. 2019).

Biomaterials are mixtures of natural substances that offer biocompatibility and they can improve the quality of life of individuals and increase longevity and comfort (Costa et al. 2019). Domskiene et al. (2019) noted that the use of biomaterials in the fashion trade is very promising, since the material can be grown as required from waste food and used clothing can be easily decomposed and biodegraded (Domskiene et al. 2019). Cellulose is one of the most abundant polymers on Earth and most of it is plant cellulose (PC), however, bacterial cellulose (BC) offers an interesting alternative (Costa et al. 
2019). According to Zhang et al. (2020), BC is a natural polymer with remarkable properties for the manufacture of biomaterials.

BC was first reported in 1988 by Brown, who identified a structure chemically equivalent to PC, through the growth of an unbranched film (Costa et al. 2019; Römling and Galperin 2015; Sederavičiūtè et al. 2019). The most effective sources for the production of BC are Acetobacter xylinum (also called Gluconacetobacter xylinum), Acetobacter hansenii and Acetobacter pasteurianus. Of these, A. xylinum has been most used for the production of commercially-available BC due to the high levels of productivity attained (Naeem et al. 2018; Wang et al. 2019).

Some authors have reported the applicability of bacterial cellulose for different purposes. Lin et al. (2020), in a recent review, address cellulose in the food industry, while Volova et al. (2019) suggested BCbased biotechnological dressings for the health sector (Lin et al. 2020; Volova et al. 2019). Furthermore, Costa et al. (2019) stated that BC is able to play a role as a substitute for other materials in the textile area and Araújo et al. (2015) developed a hydrophobic BC material which may have interesting applications for use in textile materials, clothes, flooring and other interior design materials (Araújo et al. 2015; Costa et al. 2019).

One of the ways to produce $\mathrm{BC}$ is in the production of kombucha, a probiotic drink which, according to the earliest records, originated in northeastern China in mid-220 AD. It appeared during the Chin dynasty, when a Korean doctor called "Kombu " used the "che" for treatments, thus originating the name Kombuchá (Amarasekara et al. 2020). After the Second World War, the use of Kombucha became popular in Western countries due to its multiple functional properties, and the drink subsequently spread worldwide (Dima et al. 2017; Dutta and Paul 2019; Pei et al. 2020).

Fermentation is considered to be one of the oldest methods for obtaining drinks and involves a low cost energy conservation system (Dutta and Paul 2019). BC fermentation is carried out during the tea fermentation process, generating a cellulose-based biofilm at the air-liquid interface. This is generated by the symbiotic culture of bacteria and yeasts (SCOBY) and is considered as a waste product, but it represents an important potential source of BC (Dutta and Paul 2019; Kamiński et al. 2020; Leal et al. 2018; Villarreal-Soto et al. 2018).

In the case of the textile industry, materials for the production of clothing must provide a required set of properties, such as strength, body fit and comfort. Scientists working in the textile field have recently become interested in $\mathrm{BC}$, but this material presents challenges to be overcome before it can be widely applied as a new type of textile fabric for the fashion industry (Domskiene et al. 2019). Despite offering excellent hydrophilicity for some sectors, such as biomedicine and cosmetology, due to its porous structure, this characteristic poses a problem for some uses in the textile industry (Domskiene et al. 2019; Halib et al. 2019; Kamiński et al. 2020).

In this context, the aim of this paper is to provide a bibliometric review of the academic literature focused on the hydrophilic property of $\mathrm{BC}$ and the treatments available to make it hydrophobic. Some potential 
applications of $\mathrm{BC}$ in the textile sector and the importance of future research on biomaterial, especially with regard to wettability, are discussed.

\section{Methods}

The procedure involved a bibliographic review of an analytical nature. Bibliometric analysis was carried out, mapping information from bibliographic records of documents stored in databases. The databases consulted were ScienceDirect, Proquest and Web of Science.

These databases were selected due to the large number of documents in their collections: a) ScienceDirect is considered Elsevier's most important peer-reviewed academic literature platform and has more than 3,800 journals and more than 39,000 book titles; b) Proquest: is comprised of 40 databases that provide a single source for academic journals, newspapers, reports, working papers and datasets; and c) Web of Science: makes tools available for analyzing citations, references and the h-index, to aid bibliometric analysis. It covers approximately 12,000 journals.

Figure 1 shows a flow diagram of the method used for the identification of articles to be included in this review.

As seen to Figure 1, the terms used to search for documents were "bacterial cellulose" AND hydrophobic AND textile. It should be noted that the articles to be considered in this review were selected considering the years 2015 to 2021, giving preference exclusively to academic articles and disregarding other categories of documents. The inclusion and exclusion criteria were applied by reading the title, abstract and keywords. Thus, only articles that were compatible with the research proposal were selected, that is, those related to methodologies that could be used to improve the hydrophobicity of BC.

\section{Results}

\subsection{Analysis of databases}

For each database, the search terms "bacterial cellulose" AND hydrophobic AND textiles were used. In the ScienceDirect database the results obtained were 615 documents with search terms and applying the filters document type (articles) and the time cut offs (2015-2021) resulted in 259 articles. In the Proquest database the results obtained were 379 documents with the search terms and applying the same filters resulted in 262 articles.

In the Web of Science database the results obtained were 11 documents with the search terms and applying the filters mentioned above resulted in 9 articles. Thus, a total of 531 articles were identified for further analysis. Figure 2 shows these results in graphic form.

As shown in Figure 2, a higher number of documents was identified in the ScienceDirect database, followed by ProQuest, using only the search terms. However, with the use of the "document type" and 
"time clipping" filters, there was a significant decrease compared to the ScienceDirect database. The Web of Science database provided the lowest number of relevant articles.

\subsection{Final selection and analysis of articles}

The final selection of the articles considered for the writing of this review was carried out in two stages. Stage 1 involved the reading of the title, abstract and keywords of each article. Those that were aligned with the search theme, that is, the articles that mentioned bacterial cellulose, its hydrophobicity and its use in textiles were selected. In step 2, the articles were read in full and based on the content only those that would aid the construction of the bibliometric review were selected.

In this process, the numbers of articles excluded were 231 from the ScienceDirect database, leaving 28 articles, 252 from the ProQuest database, leaving 10 articles and 4 from the Web of Science, leaving 5. Also, two articles were duplicated, one found in both the ProQuest and ScienceDirect databases and another in the ProQuest and Web of Science databases. Thus, 41 articles were considered for the review and details of this final selection process can be seen in Figure 3.

From the bibliometric process applied in this research, as shown in Figure 3, it was possible to select a set of articles that contributed to gaining a better understanding of a natural property of BC, that is, its hydrophilicity. In addition, the main focus of the articles was identified as methods to obtain more hydrophobic bacterial cellulose. It should be noted that after the exclusion of articles that were not compatible with the theme, the Science Direct database remained the largest source of articles used to carry out this review.

\subsection{Classification of articles}

The 41 articles analyzed for the writing of this document were classified according to the year of publication, the journal of publication, the country where the article was produced and the number of times the article had been cited. The purpose of this analysis was to observe the frequency and abundance of publications related to studies on the wettability of bacterial cellulose. In Supplementary Information you can access the table with the list of articles used and details.

Most of the articles were published between 2019 and 2020. Although BC has been a research topic for some time, studies on changes in its structure, such as hydrophobicity, are more recent. It was noted that in terms of the journals of publication, most of them deal with the areas of polymer science, applied and organic chemistry, biochemistry and molecular biology. Finally, the most common countries of origin of the published articles, in decreasing order, were China, Portugal, USA and Spain.

Figure 4 details the terms with the highest occurrence in the articles selected to carry out the bibliometric review.

It was clearly observed that the research focus was bacterial cellulose, this being the theme with the highest number of occurrences in the articles. Regarding the time period considered (2015 and 2021), the 
expressions hydrophilicity and superhydrophobicity appear in greater quantity after 2018. Subsequently, the studies on the use of bacterial cellulose to produce textiles gained strength, offering an alternative to leather and a move toward greater sustainability. Therefore, as noted by some authors (see below), more research is needed on the hydrophobicity of bacterial cellulose for use in the textile industry, as this is an extremely important property of textile materials, particularly in the case of a potential substitute for leather.

\subsection{The hydrophilicity properties of bacterial cellulose}

Bacterial cellulose $(\mathrm{BC})$, in addition to its mechanical resistance, has several attractive physical properties. It has higher purity compared to cellulose of plant origin, along with greater flexibility, greater hydrophilicity, tensile strength, biodegradability and transparency (Bagewadi et al. 2020; Dima et al. 2017; Martins et al. 2020; Naeem et al. 2018). The hydrophilic nature and water retention capacity of BC are influenced by the arrangement of the fibrils and the high surface area per unit of mass (Naeem et al. 2018; Shim et al. 2019; Zhang et al. 2020). Dima et al. (2017) reported a hydrophilicity of approximately 1 $\mathrm{g}$ of bacterial nanocellulose (BNC):100 ml of water, after samples of a stable aqueous suspension had been dried in an oven at $70^{\circ} \mathrm{C}$ for 3 days (Dima et al. 2017).

Untreated BC has greater hydrophilicity, indicating its naturally high wettability (Dima et al. 2017; Zhang et al. 2020). Although this is an interesting property for some sectors, without hydrophobic treatment, it limits the use of this material. According to Sederavičiūtè et al. (2019) and Martins et al. (2020), due to the hydrophilic nature of $\mathrm{BC}$, the search for stability of the material dimensions is relevant, because during drying the sample can shrink (Martins et al. 2020; Sederavičiūtè et al. 2019).

According to Bagewadi et al. (2020), Paximada et al. (2020) and Sederavičiūtè et al. (2019), BC material has a high moisture content, since water binds to the $\mathrm{OH}$ groups of the material, making it hydrophilic (Bagewadi et al. 2020; Paximada et al. 2020; Sederavičiūtė et al. 2019). The moisture content results from the microstructure of the $\mathrm{BC}$ material and affects both the physical and mechanical properties, such as density, thickness, tensile strength and plasticity. Studies have shown an increase from $91 \%$ to $98 \%$ in the water content and from $87 \%$ to $97 \%$ for $\mathrm{NaOH}$ after $8 \mathrm{~h}$ of washing (Sederavičiūte et al. 2019).

In studies reported by Bagewadi et al. (2020) and Halib et al. (2019), BC molecules lead to a highly swollen three-dimensional (3D) network and pore structures that are capable of holding a maximum of $99 \%$ water, resulting in $\mathrm{BC}$ as a promising material for obtaining highly biocompatible tissue structures (Bagewadi et al. 2020; Halib et al. 2019). Research has shown that BC (not optimized), BC (optimized) and $\mathrm{BC}$ gelatin hydrogel composites have very distinct water retention capacity (Bagewadi et al. 2020). The properties of BC can be altered by different chemical changes which can be used to improve the properties according to different applications (Halib et al. 2019).

Studies have also shown that the material properties need to be altered prior to biosynthesis (in situ), which changes the intrinsic biophysical properties, in the case of cellulose fibers through the 
incorporation of bioactive molecules, modifying the porosity and/or crystallinity of BC (Fernandes et al. 2020). Also, the application of chemical finishing can reduce the hydrophilicity of the BC film surface, potentially allowing its application under different conditions (Domskiene et al. 2019).

In addition, the $\mathrm{BC}$ water retention capacity can be varied by using different combinations of culture media, which can alter its structure and thus modify its properties (Bagewadi et al. 2020). In this way, properties similar to those of clothing fibers can be produced, depending on the parameters of the fermentation process, the application of which is growing in the fashion industry (Domskiene et al. 2019).

Due to its good biocompatibility, during immersion in a solution BC can interact with exogenous molecules, such as nanocomposites, enzymes and proteins (Fernandes et al. 2020). Although BC film has properties which attract great interest, studies show that it can undergo deformation and it is difficult to guarantee a uniform structure, thickness and porosity, and therefore the material is not durable (Domskiene et al. 2019).

For the production of textile fabrics, the thickness and uniformity of the material are priorities of great importance in the drying process, but the $\mathrm{BC}$ dimensions change and it becomes highly hydrophilic during the drying step (Domskiene et al. 2019). The application of tobacco residue extracts (without nicotine) in the BC culture medium has been used a fermentation strategy to optimize the substrate, obtaining a 1.6fold higher yield. When adding $1 \%$ of rapeseed oil to the culture medium, a $600 \%$ greater yield was obtained. Also, the improvements in the material resulted in a significant increase in the water absorption capacity and mechanical strength of the BC material (Fernandes et al. 2020).

Despite the extremely hydrophilic characteristic of BC, Wood (2019) noted that this property is not suitable for use under conditions of high humidity, which can increase with proximity to human skin. Therefore, bacterial cellulose cannot be used for domestic cleaning, for example, but research in this field continues to explore this aspect (Wood 2019).

However, recent research on hydrophilicity found that when this feature of $B C$ is desirable, there is potential for increasing this property. Jiang et al. (2020) and Sulaeva et al. (2020) reported the biological modification of bacterial cellulose $(\mathrm{BC})$ using various alginates with different molecular weights as a carbon source in the fermentation medium. According to Jiang et al. (2020), the presence of sodium alginate (SA) had a strong influence on the microstructure of the components resulting from bacterial cellulose incorporated with sodium alginate (SA-BCs) and results indicated that the hydrophilicity of SA$B C$ was strengthened and suggested the presence of a carboxyl group (Jiang et al. 2020). Sulaeva et al. (2020) found that the addition of hydrophilic alginate as a secondary component to BC-based dressings represents an elegant method of improving their moisture retention properties.

Finally, Li et al. (2020) manufactured polymer-modified carbonization bacterial cellulose (CBC) electrodes using varying amounts of cation exchange polymers (glutaric acid (GA) and sulfosuccinic acid (SSA)). The polymer-modified CBC electrodes showed good wettability, due to the addition of oxygen-containing 
groups that increase the hydrophilicity of the CBC. The high content of the hydrophilic group contributes to the excellent electrosorption performance of the electrodes prepared (Li et al. 2020).

\subsection{Studies and alternatives for a hydrophobic bacterial cellulose}

It is known that there are different possibilities for the use of BC, therefore, new alternatives for its use in association with natural products have been researched, seeking to maintain its safety and quality and also to extend its useful life (Pei et al. 2020). Bacterial cellulose (BC) can be produced in large quantities through a microbial fermentation process, providing a renewable, inexpensive, biodegradable and nontoxic biomaterial (Wang et al. 2020).

However, BC-based superhydrophobic membranes are more rarely reported, possibly due to the restricted network of cellulose nanofibrils, which can impair performance by limiting liquid infiltration (Wang et al. 2020). Most of the methods reported in the literature for the manufacture of superhydrophobic membranes involve phase separation, electrospinning, immersion coating and electrochemical approaches (Wang et al. 2020). Thus, the search for methods to improve the hydrophobicity of bacterial cellulose is an important research topic, and the main procedures investigated are detailed in Figure $\mathbf{5 .}$

The use of exogenous molecules in $\mathrm{BC}$ production, through the in situ method, leads to different results for the BC properties. In situ modification is less commonly applied, since the application of hydrophobic matrices can result in weak interfacial bonds with cellulose (hydrophilic) and chemical compatibility is therefore a prerequisite (Fernandes et al. 2020). In addition, application is suitable only for cases of polymerization in liquid solutions, where cellulose can be distributed in the polymerization medium (Fernandes et al. 2020).

Xiang and Acevedo (2017) performed studies to investigate the use of PLA fibers. To improve the mechanical and hydrophobic properties of bacterial cellulose $(B C)$, self-assembled $B C$ nanocomposites were prepared in situ using electrophilic hydrophobic acid (PLA) or PLA/lipids (PLA/Lip) as a basis for the growth of BC nanofibers (Xiang and Acevedo 2017). It was observed that using electroplated PLA mats for the $\mathrm{BC}$ culture medium led to a two-fold increase in the resistance of the material, with a $52 \%$ increase in the elongation of nanocomposites in relation to BC. The incorporation of electrospun PLA and PLA/Lip nanofiber mats decreased the moisture recovery and water vapor transmission of BC nanocomposites compared to pure BC (Xiang and Acevedo 2017).

A recent study highlights the ability of BC 3D microtopography to be precisely controlled and customized using modern engineering, and this can be used to manipulate $B C$ formation at the air-water interface through the use of hydrophobic particles and superhydrophobized surfaces (Halib et al. 2019). Thus, hydrophobic polytetrafluoroethylene (PTFE) particles were used to carry out the 3D biofabrication process, where access to oxygen around liquid marbles was promoted, as well as injection molding or printing in 3D using PTFE particles (Halib et al. 2019). The authors postulate that the high air permeability, obtained through a continuous air network generated by hydrophobic microparticles, allows high fidelity in the replication of the molds, since it generates robust biofilms. 
Another alternative for the use of hydrophobic BC was identified in a study by Hou et al. (2019). A simple modification method suitable for many other porous materials was carried out to control wetting behaviors by adjusting the hydrophobic and hydrophilic compositions of alkoxysilanes. $\mathrm{BC}^{-\mathrm{SiO}_{2}}$ membranes were firstly modified with CDMOS and then BC superhydrophobic membranes (SHBC) were obtained (Hou et al. 2019). In addition, it was found in this study that it is possible to adjust the wettability of the final membranes easily by changing the composition of alkoxysilanes in the hydrolysis process.

He et al. (2018) studied the preparation of bacterial cellulose aerogels/silica aerogels (BCAs/SAs), using $\mathrm{BC}$ as a three-dimensional self-assembled skeleton for reinforcement and silica aerogels derived from methyltriethoxysilane as the filling, through vacuum infiltration and freeze drying. The results showed superhydrophobicity with a contact angle of $152^{\circ}$ and superoleophilicity resulting from methyl groups on the surface of the silica aerogel filler (He et al. 2018).

Lin et al. (2020) prepared films with a bulky structure of BC and the surface properties showed increased hydrophobicity. They also studied biodegradable multi-layered films based on BC with the addition of sorbic acid (SA) as an antibacterial agent. The modified films showed water vapor barrier properties, at different levels of relative humidity. The antibacterial activity of the BC films with SA incorporated was altered by the concentration of both BC and SA (Lin et al. 2020).

It should be noted that the hydrophilic nature of hydroxyl groups causes low dispersion in nonpolar solvents and polymer matrices. Therefore, hydrophobization is often used to improve compatibility (Abitbol et al. 2016). In addition to the commonly used alkyl groups, these authors found that various hydrophobic groups with different functional groups (e.g., fluorine, alkenyl, alkynyl, thiol groups and pyridine moieties) can be inserted in the process. They also noted that the flexibility of these materials lies in the nature and chemistry of the cellulose surface, and with little effort the nanocellulose can become compatible with and adapted to hydrophilic and hydrophobic components.

According to Song et al. (2020), to overcome the disadvantages of hydrophilicity, previous studies on modifying the structure of $\mathrm{BC}$ chemically have been carried out, using various functional materials, such as polyethylene glycol, silver nanoparticles and zinc oxide. It was observed that these materials could be incorporated into three-dimensional BC matrices and provided greater crystallinity, porosity, hydrophobicity and mechanical properties (Song et al. 2020).

The same authors applied methods using lauryl gallate, the n-dococyl ester of gallic acid, a functional polymer useful for the modification of lignocellulose fiber, such as hardwood kraft cellulose, to nonwoven BC. The conditions of controlled oligomerization were $160 \mathrm{U} / \mathrm{ml}$ laccase and $20 \mathrm{mM}$ lauryl gallate. After the bacterial cellulose had been treated through the physical entrapment of lauryl gallate oligomers, an angle of contact with water of $88^{\circ}$ was observed and the durability of the BC was confirmed by tensile strength measurements (Song et al. 2020). 
Fernandes et al. (2019) described a process of exhaustion through the use of commercial hydrophobic polymers, a softener and a hydrophobizer based on fluorocarbon, to make the BC fiber more hydrophobic. In a similar process Araújo et al. (2015) used two different procedures. The first starts with the softener bath followed by the hydrophobic finish bath and the other starts with the hydrophobic finish bath and ends with the use of the softener bath (Araújo et al. 2015). Both methods improved the hydrophobicity of bacterial cellulose, but no studies on the disposal of these synthetics after use and the effect on the environment have been reported (Fernandes et al. 2019).

In research by Lv et al. (2016), bacterial cellulose was consecutively functionalized by magnetron sputtering and reaction with copper $(\mathrm{Cu})$ and $\mathrm{Al}_{2} \mathrm{O}_{3}$ to provide it with unique electromagnetic antioxidation shielding properties, while improving the hydrophobic, mechanical and thermal properties. The surface topography and chemical properties of $\mathrm{BC} / \mathrm{Cu} / \mathrm{Al}_{2} \mathrm{O}_{3}$ nanocomposites were examined by different techniques to verify that the metal-based nanoparticles were uniformly deposited on the surfaces. This sandwich structure of the nanocomposites increased their thermal stability, hydrophobicity, mechanical properties and electromagnetic interference (EMI) shielding effectiveness (LV et al. 2016).

Researchers have also demonstrated a new method for processing bacterial cellulose/graphene oxide (BC/GO) aerogels with multifunctional properties. They described a simple way to improve the dimensional and mechanical stability of light and hydrophilic GO-based materials, especially in humid environments. This consisted of reducing the GO, removing functional groups containing oxygen, and consequently decreasing the original hydrophilicity of the material (Pinto et al. 2020).

The morphology and dimensional stability of 3D bacterial cellulose/graphene oxide (BC/GO) aerogels can be tailored to specific needs, exploring different reduction strategies for enhanced interfacial hydrophobic-hydrophilic interactions between individual nanoelements (Pinto et al. 2020). Wang et al. (2020) found that after the carbonization process, the BC/graphene spheres showed excellent capacity to absorb oils and organic solvents due to their highly porous surface, 3D interconnected structure and high mechanical stability, giving good hydrophobicity and elasticity results (Wang et al. 2020).

Bandyopadhyay et al. (2019) carried out a study to evaluate a bacterial cellulose and guar gum (BC-GG) hydrogel film based on polyvinylpyrrolidone - carboxymethylcellulose (PVP-CMC) as an alternative for food packaging. The GG was incorporated into the PVP-CMC-BC film to increase its mechanical and barrier properties. The results showed an improvement in the elastic capacity of the PVP-CMC-BC films with the incorporation of GG and also in the barrier and hydrophobic properties. The authors reported that all films were $80 \%$ biodegraded after 28 days in vermicompost (Bandyopadhyay et al. 2019).

Shim et al. (2019) report a study where polyaniline (PANi) was entrapped in dry BC membranes. Polyaniline was produced through the green in situ polymerization of aniline by the Myceliophthora thermophila laccase at $\mathrm{pH}=4.25^{\circ} \mathrm{C}$, in the presence of a mediator, 1-hydroxybenzotriazole (HBT), using two different reactors, a water bath (WB) and an ultrasonic bath (US). They observed that the samples 
acquired hydrophobicity and showed conductive electrical behavior and a strong coloring, opening new routes for the exploration of functionalized bacterial cellulose as a green material for technical textiles, wearables and other applications (Shim et al. 2019).

Tests have also been carried out with triazine and hypocrelin. Wang et al. (2020) prepared BC membranes with modifications using triazine (TCT-BC) and grafting with hypocrelin ( $\mathrm{HC}-\mathrm{BC})$. The TCT-BC samples had a more compact surface, with smaller pores randomly distributed within the fibrous structure. It was thus assumed that a combination of intra/inter-fibril crosslinking by TCT produces a more hydrophobic surface (contact angle $h=66.7$ ). However, with the immobilization of hypocrelin on the BC surface, even smaller pores were produced, increasing the surface hydrophobicity $(h=75.5)$ (Wang et al. 2020). The modified membranes were compared with pure BC membranes.

A study by Santos et al. (2015) was aimed at the purification of BC but some hydrophobic properties were observed. The research consisted of the cultivation of $\mathrm{BC}$ and purification by two different methods: an alkaline treatment where the culture medium contained ethanol and a thermal treatment using a medium without ethanol. On comparing the untreated layers, the authors observed that the angles were greater when the $B C$ was treated with ethanol (E-BC) compared with the layers without ethanol (nE-BC). This may be because the ethanol contributed to generating a cellulose layer with a certain degree of superficial hydrophobicity. Therefore, this topic merits further research (Santos et al. 2015).

\section{Bacterial Cellulose Applications For The Textile Industry}

The textile industry, despite being an important global manufacturing sector, is directly related to negative environmental impacts resulting from the use of toxic chemicals, the consumption of huge amounts of energy and water and inadequate disposal (Luo et al. 2020; Singh et al. 2019). Therefore, to achieve a more sustainable consumption scenario, it is necessary to find solutions to reduce the negative environmental, social and economic impacts of this industry (Freudenreich and Schaltegger 2019; Ingulfsvann 2020).

One solution would be to invest in areas such as biotechnology that explore alternatives, such as the use of microorganisms, for the manufacture of textiles, both for clothing and in the footwear industry (Camere and Karana 2018; Saraç et al. 2019). Therefore, several tests have been carried out on bacterial cellulose (BC), to explore its exclusive properties, such as high purity, absence of lignin and hemicellulose, high crystallinity, high polymerization, good flexibility, tensile strength and nanofibril network structure (Chan et al. 2018; Fernandes et al. 2019; Kurniawan et al. 2012; Wang et al. 2020). BC resources grown from bacteria have been developed mainly as fine materials to replace animal leather and $B C$ has been increasingly used in tissue engineering structures (Camere and Karana 2018; Chan et al. 2018; Fernandes et al. 2019).

The application of bacterial cellulose in the fashion industry has been the focus of many studies. Chan et al. (2018) developed an innovative technique for the production of bacterial cellulose textiles called "bespoke cultivation", taking advantage of the fact that bacterial cellulose can be cultivated and grown in 
any format. This type of cultivation is suitable for producing basic fashion items, such as simple shirts, tshirts and trousers, as these items do not require complicated shapes and their timeless styles are not restricted to trends (Chan et al. 2018).

$\mathrm{Ng}$ and Wang (2015) performed tests related to the comfort and appearance of tissues obtained from bacterial cellulose. A total of 150 individuals participated in the test and the factors considered were comfort associated with touch, comfort associated with flexibility and comfort related to breathability. The result regarding the patterns analyzed was positive and it was possible to produce some prototypes of pieces of continuous 3D fashion ( $\mathrm{Ng}$ and Wang 2015).

According to Chan et al. (2018), the use of bacterial cellulose in the textile industry adheres to the concept of low to zero waste, but these materials are limited to patterns for specific types of clothing and are difficult to apply to the conventional manufacture of items of daily use. Zero waste patterns require a longer design process and more technical support for the execution of designs due to the special pattern allocation. Because it is not cost effective and is time consuming, zero waste design has not been widely used in the fashion industry (Chan et al. 2018).

Another relevant factor for the textile industry is the biodegradable nature of BC (Cazón et al. 2020; García and Prieto 2019) which could be successfully applied to obtain ecologically-friendly products (Cazón et al. 2020; Freudenreich and Schaltegger 2019). It should also be noted that for the manufacture of bacterial cellulose, only small amounts of water and energy are needed (Fernandes et al. 2020; Yim et al. 2017). Therefore, it can be considered an eco-friendly biomaterial and a mitigator of negative impacts within the textile chain.

Despite the various benefits of using bacterial cellulose, there are still many technical and practical problems associated with the manufacture of clothing that need to be resolved, such as mechanical durability, comfort, material contamination, organic acids (responsible for the characteristic unpleasant smell), and attack by microorganisms (Kamiński et al. 2020). This review addresses one such property of BC, its wettability, as can be seen in Figure 6 .

It was observed that despite its natural characteristic of being hydrophilic, which is advantageous for many applications, for instance, in the area of health, a more hydrophobic biomaterial would be of great interest for the textile industry. According to Araújo et al. (2015) and Fernandes et al. (2019), the hydrophilic nature of $\mathrm{BC}$ prevents the combination with hydrophobic polymeric matrices, presenting a challenge for the development of textiles (Araújo et al. 2015; Fernandes et al 2019).

In the textile industry, a hydrophobic cellulose material would have a wide range of applications, for instance, for clothing and impervious stain-resistant textiles, among others. Cellulose fabrics with hydrophobic fiber surfaces are suitable for producing water repellent items, as they resist water but have some porosity, which allows the transport of moisture for user comfort. Studies to reduce the hydrophilicity of the modified cellulose surface have involved different technologies with broken effects and diameters (Araújo et al. 2015). 
Although bacterial cellulose is biodegradable, renewable and biocompatible, its inherent properties, such as low strength, stiffness, high fragility and a hydrophilic nature, make it a poor biomaterial for application in commercial products (Dhar et al. 2019). However, currently, one of the main ecological problems, with regard to the textile industry and the use of clothing, is the issue of the disposal of textile waste. Since most of this waste is not biodegradable, being synthetic and derived from oil, further studies on bacterial cellulose would be of great interest (Kamiński et al. 2020)

Research seeking to improve or modify the BC properties, to address, for example, the issue of hydrophobicity, could lead to more alternative biodegradable materials being inserted in the textile market. This issue merits increased investment, as the textile sector needs to identify new sustainable materials and, therefore, offering hydrophobicity must be aligned with proposal to increase sustainability in this sector. It should be noted, however, that other relevant properties, such as durability and biodegradability, must remain unchanged (Kamiński et al. 2020).

Thus, it is clear that further studies on the applicability of BC in the textile area are needed so that this biomaterial can be applied effectively and on a large commercial scale. Finally, according to Camere and Karana (2018), engineering seeks solutions that can be expanded, rather than to produce unique artistic pieces. Interdisciplinary collaborations are indispensable in confronting the complex challenge of sustainability, and experimentation through individualistic practices, as is the case of artisanal production, will not be effective. The results of this approach can often be applied to consumer products in the near future (Camere and Karana 2018).

\section{Trends, Future Perspectives And Conclusions}

Studies on bacterial cellulose, obtained through the kombucha fermentation process, as a sustainable alternative for use as a fabric have been promising. Reduced water consumption, decreased use of insecticides and pesticides, and reduced waste, are among the advantages of using this biomaterial in the textile industry.

Several properties of bacterial cellulose, such as mechanical strength, high crystallinity and threedimensional structure, favor the use of this material in the textile industry, but its hydrophilicity poses a challenge for its application as a textile fiber. Based on the studies considered in this review, hydrophobic chemicals could be used (if other desirable properties of $\mathrm{BC}$ are maintained) to reduce the water absorption capacity, providing positive results. However, the material obtained would not be suitable for some applications, such as domestic cleaning.

The continuation of studies and tests is indispensable, so that biodegradable materials can be inserted in the textile market. Major issues to be addressed are obtaining materials with hydrophobicity and finding suitable means to dispose of the chemicals used to improve the fiber of biodegradable materials aimed at the textile market. 


\section{Declarations}

\section{Funding}

'Not applicable'

Conflicts of interest/Competing interests

The authors claim that there are no conflicts of interest.

\section{Availability of data and material}

'Not applicable'

\section{Code availability}

'Not applicable'

\section{Acknowledgments}

The authors are grateful to the Brazilian governmental agency CAPES (Higher Education Personnel Improvement Coordination) for a scholarship awarded and to the University of Southern Santa Catarina (UNISUL) for offering one of the authors the opportunity to pursue a master's degree in Environmental Sciences.

\section{References}

Abitbol T, Rivkin A, Cao Y, Nevo Y, Abraham E, Ben-Shalom T, Lapidot S, Shoseyov, O. (2016) Nanocellulose, a tiny fiber with huge applications. Current Opinion in Biotechnology, 39(I), 76-88. https://doi.org/10.1016/j.copbio.2016.01.002

Amarasekara AS, Wang D, Grady TL (2020) A comparison of kombucha SCOBY bacterial cellulose purification methods. SN Applied Sciences, 2(2). https://doi.org/10.1007/s42452-020-1982-2

Araújo S, Silva FM da, Gouveia IC (2015) The Role of Technology Towards a New Bacterial-Cellulosebased Material for Fashion Design. Journal of Industrial and Intelligent Information, 3(2), 168-172. https://doi.org/10.12720/jiii.3.2.168-172

Bagewadi ZK, Bhavikatti JS, Muddapur UM, Yaraguppi DA, Mulla SI (2020) Statistical optimization and characterization of bacterial cellulose produced by isolated thermophilic Bacillus licheniformis strain ZBT2. Carbohydrate Research, 491(February), 107979. https://doi.org/10.1016/j.carres.2020.107979

Bandyopadhyay S, Saha N, Brodnjak UV, Sáha P (2019) Bacterial cellulose and guar gum based modified PVP-CMC hydrogel films: Characterized for packaging fresh berries. Food Packaging and Shelf Life, 22(September). https://doi.org/10.1016/j.fpsl.2019.100402 
Camere S, Karana E (2018) Fabricating materials from living organisms: An emerging design practice. Journal of Cleaner Production, 186, 570-584. https://doi.org/10.1016/j.jclepro.2018.03.081

Cazón P, Velázquez G, Vázquez M (2020) Bacterial cellulose films: Evaluation of the water interaction. Food Packaging and Shelf Life, 25(May), 100526. https://doi.org/10.1016/j.fpsl.2020.100526

Chan CK, Shin J, Jiang SXK (2018) Development of Tailor-Shaped Bacterial Cellulose Textile Cultivation Techniques for Zero-Waste Design. Clothing and Textiles Research Journal, 36(1), 33-44. https://doi.org/10.1177/0887302X17737177

Correia MF Silva PC (2019) Cleaner Production in the textile industry and its relationship to sustainable development goals. Journal of Cleaner Production, 228, 1514-1525. https://doi.org/10.1016/j.jclepro.2019.04.334

Costa AF de S, de Amorim JDP, Almeida FCG, de Lima ID, de Paiva SC, Rocha M AV, Vinhas GM, Sarubbo LA (2019) Dyeing of bacterial cellulose films using plant-based natural dyes. International Journal of Biological Macromolecules, 121, 580-587. https://doi.org/10.1016/j.ijbiomac.2018.10.066

Dhar P, Pratto B, Gonçalves AJC, Bankar S (2019) Valorization of sugarcane straw to produce highly conductive bacterial cellulose / graphene nanocomposite films through in situ fermentation: Kinetic analysis and property evaluation. Journal of Cleaner Production, 238, 117859. https://doi.org/10.1016/j.jclepro.2019.117859

Dima SO, Panaitescu DM, Orban C, Ghiurea M, Doncea SM, Fierascu RC et al (2017) Bacterial nanocellulose from side-streams of kombucha beverages production: Preparation and physical-chemical properties. Polymers, 9(8), 5-10. https://doi.org/10.3390/polym9080374

Domskiene J, Sederaviciute F, Simonaityte J (2019) Kombucha bacterial cellulose for sustainable fashion. International Journal of Clothing Science and Technology, 31(5), 644-652. https://doi.org/10.1108/IJCST-02-2019-0010

Dutta H, Paul SK (2019) Kombucha Drink: Production, Quality, and Safety Aspects. In Production and Management of Beverages. https://doi.org/10.1016/b978-0-12-815260-7.00008-0

Fernandes I de AA, Pedro AC, Ribeiro VR, Bortolini DG, Ozaki MSC, Maciel GM, Haminiuk CWI (2020) Bacterial cellulose: From production optimization to new applications. International Journal of Biological Macromolecules, 164, 2598-2611. https://doi.org/10.1016/j.jibiomac.2020.07.255

Fernandes M, Gama M, Dourado F, Souto AP (2019) Development of novel bacterial cellulose composites for the textile and shoe industry. Microbial Biotechnology, 12(4), 650-661. https://doi.org/10.1111/17517915.13387

Fernandes M, Souto AP, Gama M, Dourado F (2019) Bacterial cellulose and emulsified AESO biocomposites as an ecological alternative to leather. Nanomaterials, 9(12), 1-18. 
Freudenreich B, Schaltegger S (2019) Developing sufficiency-oriented offerings for clothing users: Journal of Cleaner Production, 1-23. https://doi.org/10.1016/j.jclepro.2019.119589

García C, Prieto MA (2019) Bacterial cellulose as a potential bioleather substitute for the footwear industry. Microbial Biotechnology, 12(4), 582-585. https://doi.org/10.1111/1751-7915.13306

Halib N, Ahmad I, Grassi M, Grassi G (2019) The remarkable three-dimensional network structure of bacterial cellulose for tissue engineering applications. International Journal of Pharmaceutics, 566(June), 631-640. https://doi.org/10.1016/j.ijpharm.2019.06.017

He J, Zhao H, Li X, Su D, Zhang F, Ji H, Liu R (2018) Superelastic and superhydrophobic bacterial cellulose/silica aerogels with hierarchical cellular structure for oil absorption and recovery. Journal of Hazardous Materials, 346, 199-207. https://doi.org/10.1016/j.jhazmat.2017.12.045

Hou Y, Duan C, Zhu G, Luo H, Liang S, Jin Y, et al (2019). Functional bacterial cellulose membranes with 3D porous architectures: Conventional drying, tunable wettability and water/oil separation. Journal of Membrane Science, 591(July), 117312. https://doi.org/10.1016/j.memsci.2019.117312

Ingulfsvann AS (2020) What does the brand tell us? e Sustainability and responsibility in a circular perspective. Journal of Cleaner Production, 246, 118993. https://doi.org/10.1016/j.jclepro.2019.118993

Jiang Y, Yu G, Zhou Y, Liu Y, Feng Y, Li J (2020) Effects of sodium alginate on microstructural and properties of bacterial cellulose nanocrystal stabilized emulsions. Colloids and Surfaces $A$ :

Physicochemical and Engineering Aspects, 607(May), 125474.

https://doi.org/10.1016/j.colsurfa.2020.125474

Kamiński K, Jarosz M, Grudzień J, Pawlik J, Zastawnik F, Pandyra P, Kołodziejczyk AM (2020) Hydrogel bacterial cellulose: a path to improved materials for new eco-friendly textiles. Cellulose, 27(9), 53535365. https://doi.org/10.1007/s10570-020-03128-3

Kurniawan H, Lai JT, Wang MJ (2012) Biofunctionalized bacterial cellulose membranes by cold plasmas. Cellulose, 19(6), 1975-1988. https://doi.org/10.1007/s10570-012-9785-2

Leal JM, Suárez LV, Jayabalan R, Oros JH, Escalante-Aburto A (2018) A review on health benefits of kombucha nutritional compounds and metabolites. CYTA - Journal of Food, 16(1), 390-399. https://doi.org/10.1080/19476337.2017.1410499

Li D, Ning X, Yuan Y, Hong Y, Zhang J (2020) lon-exchange polymers modified bacterial cellulose electrodes for the selective removal of nitrite ions from tail water of dyeing wastewater. Journal of Environmental Sciences (China), 91, 62-72. https://doi.org/10.1016/j.jes.2020.01.002 
Lin D, Liu Z, Shen R, Chen S, Yang X (2020) Bacterial cellulose in food industry: Current research and future prospects. International Journal of Biological Macromolecules, 158, 1007-1019.

https://doi.org/10.1016/j.jjbiomac.2020.04.230

Luo Y, Pei L, Wang J (2020) Sustainable indigo dyeing and improvement of rubbing fastness of dyed cotton $\mathrm{fi}$ ber using different $\mathrm{fi}$ xing agents for obtaining eco- friendly cowboy products. Journal of Cleaner Production, 251, 119728. https://doi.org/10.1016/j.jclepro.2019.119728

Lv P, Xu W, Li D, Feng Q, Yao Y, Pang Z, et al (2016) Metal-based bacterial cellulose of sandwich nanomaterials for anti-oxidation electromagnetic interference shielding. Materials and Design, 112, 374382. https://doi.org/10.1016/j.matdes.2016.09.100

Martins D, Estevinho B, Rocha F, Dourado F, Gama M (2020) A dry and fully dispersible bacterial cellulose formulation as a stabilizer for oil-in-water emulsions. Carbohydrate Polymers, 230(July 2019), 115657. https://doi.org/10.1016/j.carbpol.2019.115657

Naeem MA, Lv P, Zhou H, Naveed T, Wei Q (2018) A novel in situ self-assembling fabrication method for bacterial cellulose-electrospun nanofiber hybrid structures. Polymers, 10(7).

https://doi.org/10.3390/polym10070712

Ng MCF, Wang W (2015) A Study of the Receptivity to Bacterial Cellulosic Pellicle for Fashion. Research Journal of Textile and Apparel, 19(4), 65-69. https://doi.org/10.1108/RJTA-19-04-2015-B007

Paximada P, Kanavou E, Mandala IG (2020) Effect of rheological and structural properties of bacterial cellulose fibrils and whey protein biocomposites on electrosprayed food-grade particles. Carbohydrate Polymers, 241(February), 116319. https://doi.org/10.1016/j.carbpol.2020.116319

Pei J, Jin W, Abd El-Aty AM, Baranenko DA, Gou X, Zhang H, et al (2020) Isolation, purification, and structural identification of a new bacteriocin made by Lactobacillus plantarum found in conventional kombucha. Food Control, 110, 106923. https://doi.org/10.1016/j.foodcont.2019.106923

Pinto SC, Gonçalves G, Sandoval S, López-Periago AM, Borras A, Domingo C, et al (2020) Bacterial cellulose/graphene oxide aerogels with enhanced dimensional and thermal stability. Carbohydrate Polymers, 230(October 2019), 115598. https://doi.org/10.1016/j.carbpol.2019.115598

Römling U, Galperin MY (2015) Bacterial cellulose biosynthesis: Diversity of operons, subunits, products, and functions. Trends in Microbiology, 23(9), 545-557. https://doi.org/10.1016/j.tim.2015.05.005

Sandvik IM, Stubbs W (2017) Circular fashion supply chain through textile-to-textile recycling. Journal of Fashion Marketing and Management, 23(3), 366-381. https://doi.org/10.1108/JFMM-04-2018-0058

Santos SM, Carbajo JM, Quintana E, Ibarra D, Gomez N, Ladero M, et al (2015) Characterization of purified bacterial cellulose focused on its use on paper restoration. Carbohydrate Polymers, 116, 173181. https://doi.org/10.1016/j.carbpol.2014.03.064 
Saraç EG, Öner E, Kahraman MV (2019) Microencapsulated organic coconut oil as a natural phase change material for thermo-regulating cellulosic fabrics. Cellulose, 9, 1-12.

https://doi.org/10.1007/s10570-019-02701-9

Sederavičiūtè F, Bekampienè P, Domskienè J (2019) Effect of pretreatment procedure on properties of Kombucha fermented bacterial cellulose membrane. Polymer Testing, 78(February).

https://doi.org/10.1016/j.polymertesting.2019.105941

Shim E, Su J, Noro J, Teixeira M A, Cavaco-Paulo A, Silva C, Kim HR (2019) Conductive bacterial cellulose by in situ laccase polymerization of aniline. PLOS ONE, 14(4), 1-15.

https://doi.org/10.1371/journal.pone.0214546

Singh J, Cooper T, Cole C, Gnanapragasam A, Shapley M (2019) Evaluating approaches to resource management in consumer product sectors - An overview of global practices. Journal of Cleaner Production, 224, 218-237. https://doi.org/10.1016/j.jclepro.2019.03.203

Song, JE, Cavaco-Paulo A, Silva C, Kim HR (2020) Improvement of bacterial cellulose nonwoven fabrics by physical entrapment of lauryl gallate oligomers. Textile Research Journal, 90(2), 166-178. https://doi.org/10.1177/0040517519862886

Sulaeva I, Hettegger H, Bergen A, Rohrer C, Kostic M, Konnerth J et al (2020). Fabrication of bacterial cellulose-based wound dressings with improved performance by impregnation with alginate. Materials Science and Engineering C, 110 (November 2019), 110619. https://doi.org/10.1016/j.msec.2019.110619

Villarreal-Soto SA, Beaufort S, Bouajila J, Souchard J P, Taillandier P (2018) Understanding Kombucha Tea Fermentation: A Review. Journal of Food Science, 83(3), 580-588. https://doi.org/10.1111/17503841.14068

Volova TG, Shumilova AA, Nikolaeva ED, Kirichenko AK, Shishatskaya El (2019) Biotechnological wound dressings based on bacterial cellulose and degradable copolymer $\mathrm{P}(3 \mathrm{HB} / 4 \mathrm{HB})$. International Journal of Biological Macromolecules, 131, 230-240. https://doi.org/10.1016/j.ijbiomac.2019.03.068

Wang F, Zhao X, Wahid F, Zhao X, Qin X, Bai H et al (2020) Sustainable, superhydrophobic membranes based on bacterial cellulose for gravity-driven oil/water separation. Carbohydrate Polymers, (June), 117220. https://doi.org/10.1016/j.carbpol.2020.117220

Wang J, Tavakoli J, Tang Y (2019) Bacterial cellulose production, properties and applications with different culture methods - A review. Carbohydrate Polymers, 219(April), 63-76.

https://doi.org/10.1016/j.carbpol.2019.05.008

Wang T, Xu L, Shen H, Cao X, Wei Q, Ghiladi RA, Wang Q (2020) Photoinactivation of bacteria by hypocrellin-grafted bacterial cellulose. Cellulose, 27(2), 991-1007. https://doi.org/10.1007/s10570-01902852-9 
Wood J (2019) Bioinspiration in Fashion - A Review. Biomimetics, 4(1), 16.

https://doi.org/10.3390/biomimetics4010016

Xiang C, Acevedo N (2017) In Situ Self-Assembled Nanocomposites from Bacterial Cellulose Reinforced with Eletrospun Poly(lactic acid)/Lipids Nanofibers. Polymers, 9(12), 179.

https://doi.org/10.3390/polym9050179

Yim SM, Song JE, Kim HR (2017) Production and characterization of bacterial cellulose fabrics by nitrogen sources of tea and carbon sources of sugar. Process Biochemistry, 59, 26-36.

https://doi.org/10.1016/j.procbio.2016.07.001

Zhang S, Li L, Ren X, Huang TS (2020) N-halamine modified multiporous bacterial cellulose with enhanced antibacterial and hemostatic properties. International Journal of Biological Macromolecules, 161, 1070-1078. https://doi.org/10.1016/j.ijbiomac.2020.06.053

Zhang Y, Chen Y, Cao G, Ma X, Zhou J, Xu W (2020) Bacterial cellulose production from terylene ammonia hydrolysate by Taonella mepensis WT-6. International Journal of Biological Macromolecules, 104743. https://doi.org/10.1016/j.ijbiomac.2020.10.172

\section{Figures}

- Web of Science

- ProQuest

- Science Direct

\section{Database}

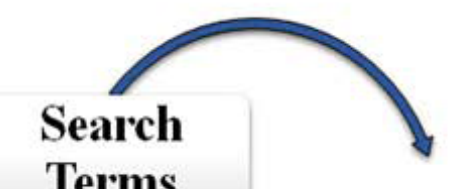

Terms

- "Bacterial cellulose" AND hydrophobic AND textile

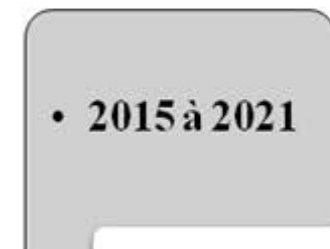

Timeframe

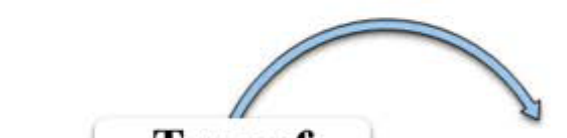

Type of Document

- Academic articles

- Title
- Abstract

- Keywords

Analysis

\section{Figure 1}


Flow diagram of the method used for the identification of relevant articles (source: the authors).

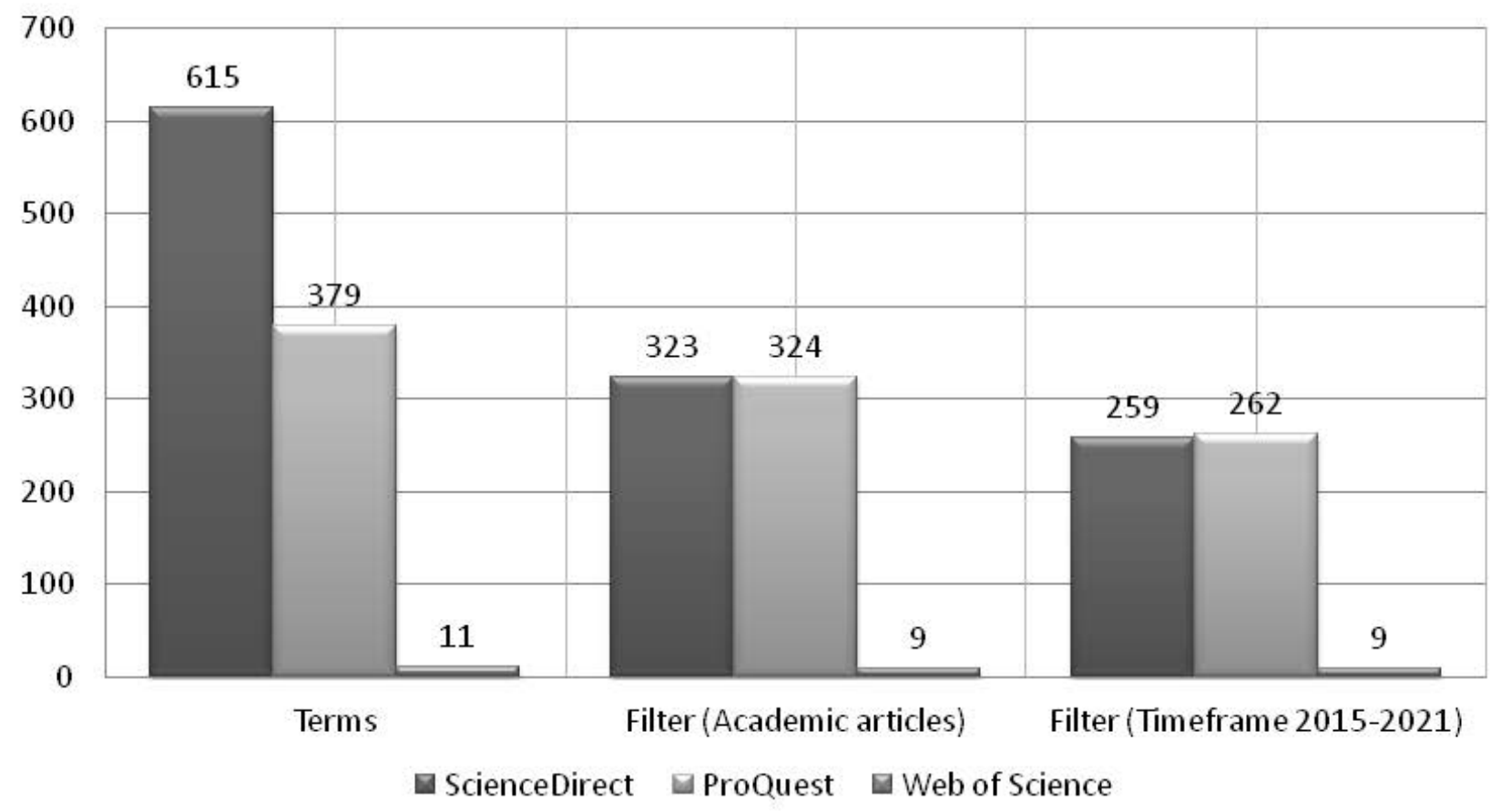

\section{Figure 2}

Graph showing the search results for the databases and after applying the filters (source: the authors).
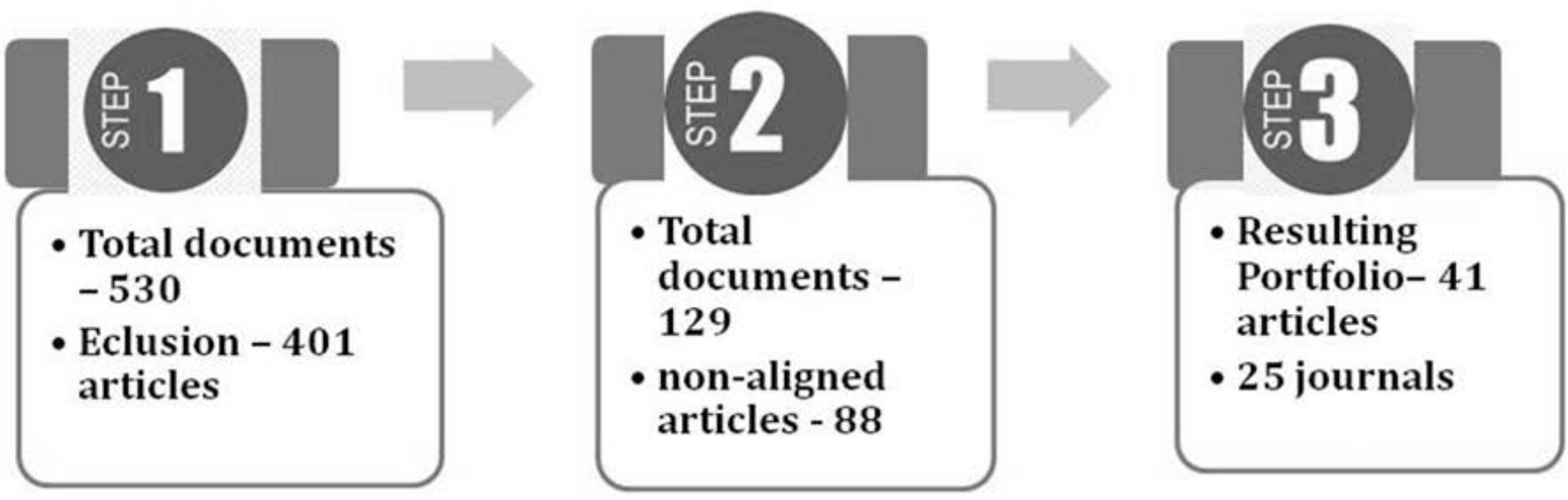


\section{Figure 3}

Final selection of articles used for the bibliometric analysis (source: the authors).

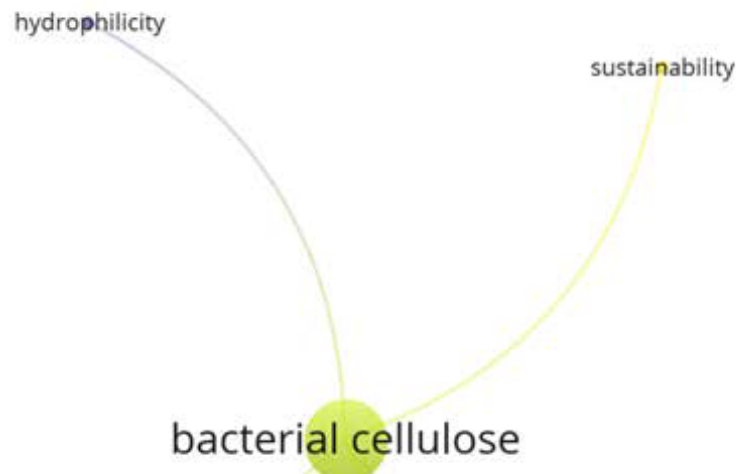

superhydrophobic

\& VOSviewer

bacterial cellulose textile

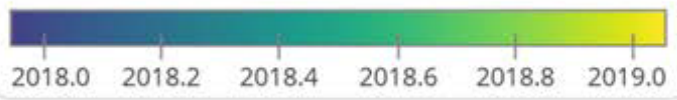

\section{Figure 4}

Clusters of correlated in the articles analyzed (source: the authors). 


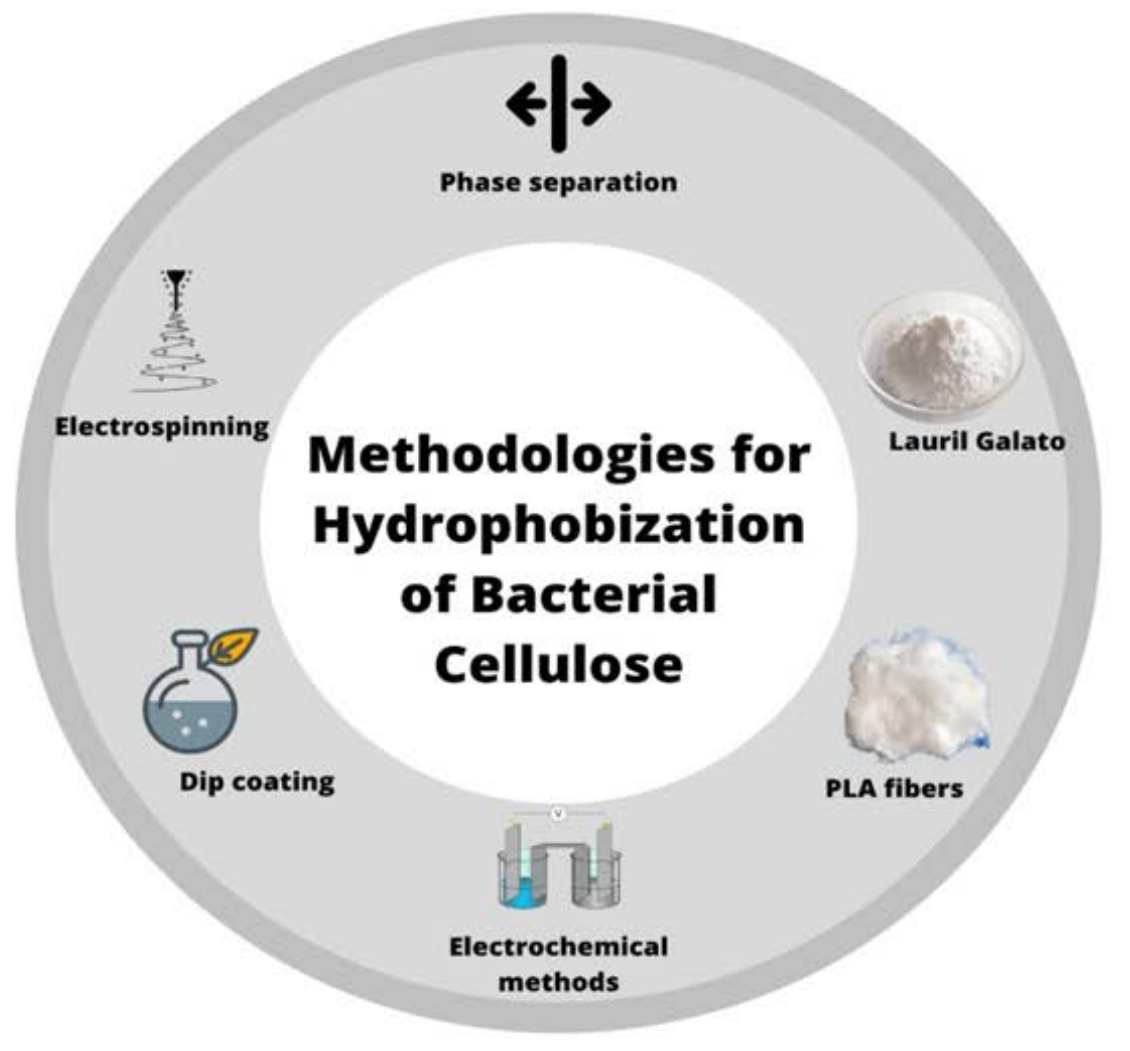

Figure 5

List of methodologies studied for obtaining hydrophobic bacterial cellulose (source: the authors).

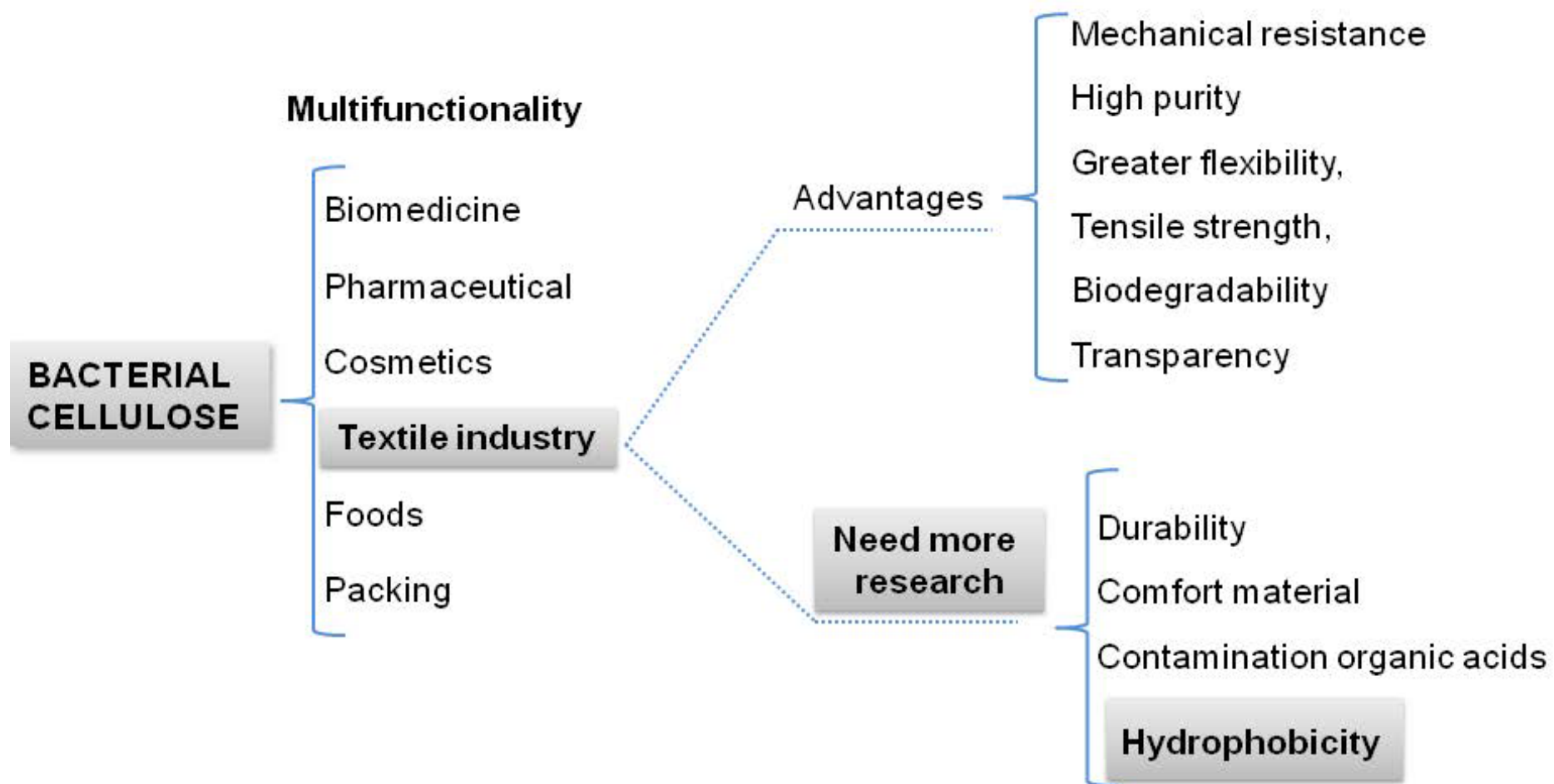


Figure 6

The hydrophobicity of bacterial cellulose is an area of study that merits further scientific investigation for its use in the textile industry (source: the authors).

\section{Supplementary Files}

This is a list of supplementary files associated with this preprint. Click to download.

- Supplementarylnformation.docx 